\title{
Acta
Biochimica
Polonica
}

Vol. 52 No. 1/2005

$221-232$

QUARTERLY

\section{Functional relationships between the Saccharomyces cerevisiae cis-prenyltransferases required for dolichol biosynthesis}

\author{
Kariona Grabińska ${ }^{1,2}$, Grażyna Sosińska ${ }^{1}$, Jacek Orłowski ${ }^{1}$, Ewa Swiezewska ${ }^{1}$, \\ Thierry Berges $^{2}$, Francis Karst ${ }^{2}$ and Grażyna Palamarczyk ${ }^{1 凶}$ \\ ${ }^{1}$ Institute of Biochemistry and Biophysics, Polish Academy of Sciences, Warszawa, Poland; \\ ${ }^{2}$ Laboratoire de Genetique de la Levure, Université de Poitiers, France
}

Received: 22 December, 2004; accepted: 18 February, 2005

Key words: yeast, cis-prenyltransferases, farnesyl diphosphate synthase, cross talk

In the yeast Saccharomyces cerevisiae the RER2 and SRT1 genes encode Rer2 and Srt1 proteins with cis-prenyltransferase (cis-PT-ase) activity. Both cis-PT-ases utilize farnesyl diphosphate (FPP) as a starter for polyprenyl diphosphate (dolichol backbone) formation. The products of the Rer2 and Srt1 proteins consist of 14-17 and 18-23 isoprene units, respectively. In this work we demonstrate that deletion or overexpression of $S R T 1$ up-regulates the activity of Rer2p and dolichol content. However, upon overexpression of SRT1, preferential synthesis of longer-chain dolichols and a decrease in the amount of the shorter species are observed. Furthermore, overexpression of the ERG20 gene (encoding farnesyl diphosphate synthase, Erg20p) induces transcription of SRT1 mRNA and increases the levels of mRNA for RER2 and DPM1 (dolichyl phosphate mannose synthase, Dpm1p). Subsequently the enzymatic activity of Rer2p and dolichol content are also increased. However, the amount of Dpm1p or its enzymatic activity remain unchanged.

The early steps in dolichol biosynthesis are quinone (Jung \& Tanner, 1973; Adair \& identical to those leading to sterol and ubiCafmeyer, 1987). These biosynthetic path-

\footnotetext{
This work was supported by the State Committee for Scientific Research (KBN 6P04A 007)

Present address: Université Louis Pasteur, INRA, Colmar, France.

${ }^{\bowtie}$ Correspondence to: Grażyna Palamarczyk, Institute of Biochemistry and Biophysics, A. Pawińskiego 5a, 02-106 Warszawa, Poland; tel: (48 22) 658 4702; fax: (48 39) 121 623; e-mail: gp@ibb.waw.pl Abbreviations: cis-PT-ase, cis-prenyltransferase; DMAPP, dimethylallyl diphosphate; FPP, farnesyl diphosphate; GPI, glycosyl phosphatidyl inositol; GPP, geranyl diphosphate; IPP, isopentenyl diphosphate; OT, disacharyltransferase.
} 
ways diverge after the synthesis of farnesyl diphosphate (FPP) by FPP-synthase encoded by the ERG20 gene (see Fig. 1). Erg20p catalyses two sequential condensations of the 5-carbon unit dimethylallyl diphosphate (DMAPP) with isopentenyl diphosphate (IPP) to form geranyl diphosphate (GPP) and then GPP with another IPP molecule to form FPP. In wild type $S$. cerevisiae Erg20p produces FPP and GPP in the molar ratio 75:25 (Blanchard \& Karst, 1993).

A cis-PT-ase is considered to be the first enzyme committed to dolichol biosynthesis (Adair \& Cafmeyer, 1987), catalyzing 1'-4 condensation of farnesyl (di-trans prenyl) diphosphate (FPP) with 11 to 15 isopentenyl diphosphate (IPP) units to form polyprenyl diphosphate (dehydro- dolichyl diphosphate) of appropriate chain length. This reaction is followed by dephosphorylation and reduction of dehydro-dolichyl diphosphate to dolichol followed by rephosphorylation of the latter by CTP-dependent dolichol kinase (Szkopinska et al., 1988; Sagami et al., 1996; Burda \& Aebi, 1999). Mono- and oligosaccharide derivatives of dolichyl phosphate are required in $\mathrm{N}$-glycosylation, O-mannosylation and glycosyl phosphatidyl inositol (GPI) protein anchor formation.

The length of dolichol molecules synthesized in the yeast $S$. cerevisiae by Rer2 protein and most prevalent, at the logarithmic phase of growth (Sato et al., 1999), is 14-17 isoprene units $\left(\mathrm{C}_{70}-\mathrm{C}_{85}\right)$ (Jung \& Tanner, 1973). rer2 mutants of $S$. cerevisiae show characteristic phenotypes, i.e. slow and thermosensitive growth, sensitivity to hygromycin B and resistance to orthovanadate, abnormal accumulation of endoplasmic reticulum (ER) and Golgi membranes as well as defects in $\mathrm{N}$ - and O-glycosylation. Deletion of the RER2 gene results in the slow growth and is concomitant with a decrease of cis-PT-ase activity to $2.7 \%$ of that in the wild type. However, after several generations some RER2 deleted cells ( $\Delta$ rer2) exhibit a wild type phenotype due to the compensatory effect of the SRT1 gene, which is up-regulated in the absence of the RER2 gene, and they synthesize dolichols that are unusually long for yeast and contain 19-22 isoprene units, similar to mammalian dolichols (Schenk et al., 2001; Sato et al., 2001). Rer2p and Srt1p are localized to different cellular compartments: Rer2p is linked to the outer side of the ER membrane, and Srt1p occurs in lipid bodies (Sato et al., 1999; 2001). Induction of the $S R T 1$ gene, but not of $R E R 2$, is observed in the stationary phase of growth (Sato et al., 2001). On the other hand, synthesis of long chain dolichols in early logarithmic phase upon transfer of yeast into starvation medium has been reported (Szkopinska et al., 2002). Moreover, as we have described previously (Szkopinska et al., 1997), overexpression of the erg20-2 gene encoding mutated Erg20p (Lys197Glu substitution), which is defective in the enzymatic activity (Blanchard \& Karst, 1993) results also in the synthesis of long chain polyprenols and dolichols, containing up to 24 isoprene residues in the logarithmic phase of growth. This effect was concomitant with an eight fold increase in the amount of dolichols and induction of the synthesis of poliprenols (dehydrodolichols) as compared to dolichols synthesized in the wild type yeast. Synthesis of long-chain polyprenols and dolichols was also observed upon overexpression of the SRT1 gene in the $\Delta$ rer2 cells (Sato et al., 2001).

In the present work we demonstrate that dolichol biosynthesis in $S$. cerevisiae might be affected by a post-transcriptional interaction between RER2 and SRT1 encoded proteins or/and their end products. Moreover, overexpression of the ERG20 gene specifically induces SRT1 and up-regulates RER2 and DPM1 gene expression. In consequence, the activity of Rer2p and dolichol content are increased but the level of Dpm1p and its enzymatic activity remain unchanged.

In conclusion we discuss functional interactions between cis-PT-ases and FPPS or/and their products in dolichol biosynthesis. 


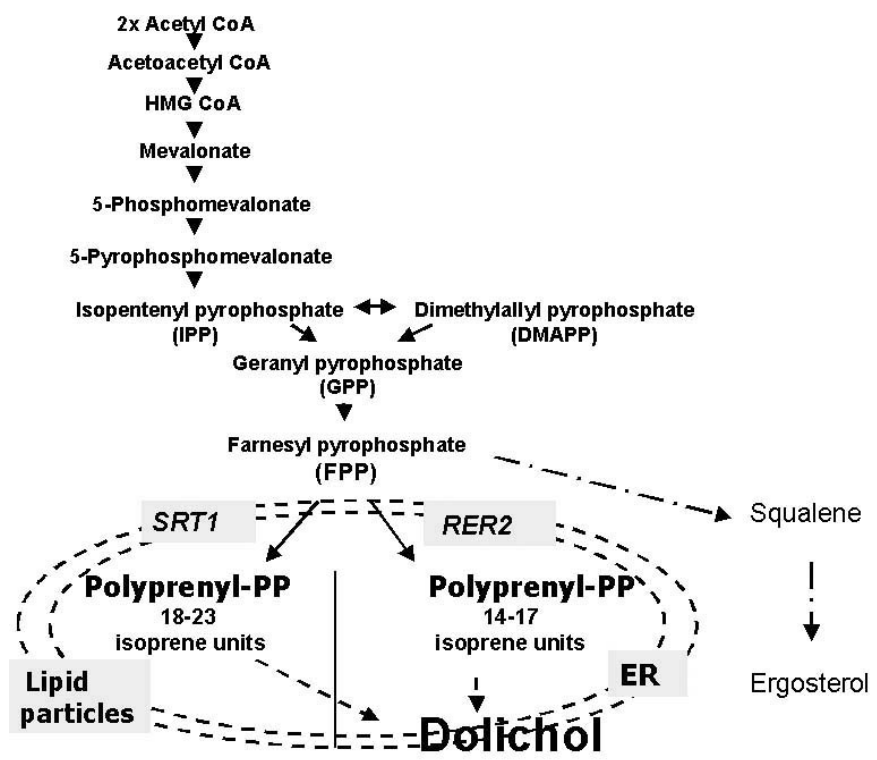

Figure 1. Outline of the dolichol biosynthetic pathway in S. cerevisiae according to Grabińska \& Palamarczyk, 2002).

\section{MATERIAL AND METHODS}

Chemicals. All reagents were of analytical grade. Dehydro-dolichol and dolichol standards were obtained from the Collection of Polyprenols of the Institute of Biochemistry and Biophysics (Warsaw). [ $\left.{ }^{14} \mathrm{C}\right]$ Isopentenyl diphosphate (58 mCi/mmol) was from Amersham, U.K.

Yeast strains and plasmids. The strains used in the study are listed in Table1. Plasmid pDD5 was described previously (Szkopinska et al., 1997). pSRT1 was constructed as follows: the SRT1 gene coding sequence was amplified by PCR with oligonucleotides: SRT1ATG: 5'-ATGAAAATGCCCAGTATT-3' and SRT1-3: 5' CCCGGG CTTTTACT TATTCA-
TCTCC-3', cloned into pGEM-T Easy Vector (Promega) and subcloned into the NotI restriction site of $\mathrm{pNEV}-1$ replicative vector containing the PMA1 yeast gene promoter and terminator (Palmgreen et al., 1991).

Media and growth condition. Yeast cells were grown at $28^{\circ} \mathrm{C}$ in synthetic complete YNB $(0.67 \%$ yeast nitrogen base and mixture of amino acids and nucleotides to final concentration 20-30 mg/l with nutrition markers omitted) medium with $2 \%$ glucose or galactose as a carbon source. Membrane fraction was prepared according to the method described in (Lehle \& Tanner, 1974).

Northern blot analysis. Total RNA was prepared from exponentially growing yeast cells $\left(\mathrm{A}_{600}=0.5-0.8\right)$ according to the method

Table 1. Yeast strains used in the study

\begin{tabular}{|c|c|c|}
\hline Strain name & Genotype & Source \\
\hline BY4742 & Mat $\alpha$; his $3 \Delta 1$; leu $2 \Delta 1$; lys $2 \Delta 1$; ura $3 \Delta 1$; & EUROSCARF \\
\hline BY4742pDD5 & BY4742 $2 \mu \mathrm{p}_{\mathrm{CAL} / \mathrm{CYC} 1} E R G 20$ & This study \\
\hline BY4742 $\Delta r e r 2$ & as for BY4742, rer2::kanMX4 & EUROSCARF \\
\hline 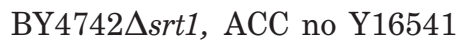 & as for BY4742, srt1::kanMX4 & EUROSCARF \\
\hline $\mathrm{BY} 4742 \mathrm{p} S R T 1$ & As for BY4742 $2 \mu$ р рим $S R T 1$ & This study \\
\hline
\end{tabular}


described earlier (Cordier et al., 1999). Twenty micrograms of total RNA were separated in a $1.2 \%$ denaturing agarose gel containing $12.32 \mathrm{M}$ formaldehyde, and blotted onto a nylon membrane (Hybond $\mathrm{N}$ Amersham). Hybridization and washes were performed as described previously (Cordier et al., 1999). Transcripts for the ACT1, SRT1, RER2, ERG20, SEC59 and DPM1 genes were visualized using specific $\left[{ }^{32} \mathrm{P}\right] \mathrm{dATP}$-labeled DNA probes. Gene expression was quantified using the Gene Tools v. 3.00 (Syngene) computer software and presented as the ratio of mRNA of a given gene to the mRNA level of ACT1.

Western blot analysis. Membrane proteins from the strains tested were separated by SDS/PAGE electrophoresis at $20 \mu \mathrm{g}$ per lane. Separated proteins were transferred to Immobilon $^{\text {TM }}$ (Millipore) and probed with anti-S. cerevisiae Dpm1p monoclonal antibody (Molecular Probes) and anti-mouse IgG alkaline phosphatase conjugated (Sigma). Alkaline phosphatase activity was detected with the BCIP/NBT detection system (Promega) according to the manufacturer's protocol.

Cis-prenyltransferase activity. The incubation mixture contained, in a final volume of $250 \mu \mathrm{l}, 50 \mathrm{mM}$ sodium phosphate buffer, $0.5 \mathrm{mM} \mathrm{MgCl}_{2}, 20 \mathrm{mM}$ 2-mercaptoethanol, 10 $\mathrm{mM} \mathrm{KF}, 3 \times 10^{5}$ c.p.m. radiolabeled $\left[{ }^{14} \mathrm{C}\right] \mathrm{IPP}$ $(58 \mathrm{mCi} / \mathrm{mmol})$ and $500 \mu \mathrm{g}$ of membrane protein. After $90 \mathrm{~min}$ of incubation at $30^{\circ} \mathrm{C}$, the reaction was terminated by addition of $4 \mathrm{ml}$ of chloroform/methanol (3:2, v/v). The mixture was washed three times with $1 / 5$ volume of $10 \mathrm{mM}$ EDTA in $0.9 \% \mathrm{NaCl}$. The organic phase was concentrated under a stream of nitrogen and subjected to thin-layer chromatography on HPTLC RP-18 plates. The gel from the zone containing radiolabeled polyprenols was scraped and subjected to liquid scintillation counting.

Farnesyl diphosphate synthase activity. Cells were grown in minimal medium. The cell-free extracts were prepared in $50 \mathrm{mM}$ phosphate buffer, pH 7.5 (Cordier et al.,
1999). The reaction mixture $(100 \mathrm{ml})$ containing $50 \mathrm{mM}$ phosphate buffer, $\mathrm{pH} 7.5,200 \mu \mathrm{M}$ allylic substrate (DMAPP or GPP), $5 \mu \mathrm{M}$ $\left[{ }^{14} \mathrm{C}\right] \mathrm{IPP}$ ( $58 \mathrm{mCi} / \mathrm{mmol}$ ), $55 \mu \mathrm{M}$ IPP, $1 \mathrm{mM}$ $\mathrm{MgCl}_{2}, 5 \mathrm{mM}$ iodoacetamide and $105000 \times \mathbf{g}$ supernatant (10-60 $\mu \mathrm{g}$ of protein) was incubated at $37^{\circ} \mathrm{C}$ for $5 \mathrm{~min}$ and rapidly ice-chilled. Then $0.5 \mathrm{ml}$ of water was added, followed by $1 \mathrm{ml}$ of hexane and $0.2 \mathrm{ml}$ of $1 \mathrm{M} \mathrm{HCl}$ (for dephosphorylation), and the samples were shaken for $15 \mathrm{~min}$ at $37^{\circ} \mathrm{C}$. The mixture was ice-chilled and vigorously mixed. The separated upper phase was washed three times with water and subjected to TLC on HPTLC RP-18 plates in acetone/water (5:2, v/v). Radioactive compounds, visualised by autoradiography, were identified by cochromatography with unlabeled standards, scraped from the plates and quantified by liquid scintillation counting.

Measurements of geraniol:farnesol ratio. The assay conditions were as described previously (Chambon et al., 1990) with the following modifications: $200 \mu \mathrm{M}$ DMAPP was used as allylic substrate and $11 \mu \mathrm{M}\left[{ }^{14} \mathrm{C}\right] \mathrm{IPP}$ as the homoallylic one; reaction time was $15 \mathrm{~min}$. Reaction products after dephosphorylation and extraction into the hexane phase were analysed on HPTLC RP-18 plates (as above). Geraniol and farnesol spots were identified by internal standards, scraped from the plates and quantified by liquid scintillation counting.

Characterization of dolichols synthesized in vivo. The membrane fraction mixed with an internal standard (dolichol containing 11 isoprene units, $\mathrm{C}_{55}$ ) was extracted with chloroform/methanol $(3: 2, \mathrm{v} / \mathrm{v})$ and centrifuged. The organic supernatant was washed three times with $1 / 5$ volume of $10 \mathrm{mM}$ EDTA in $0.9 \% \mathrm{NaCl}$ and evaporated to dryness. Subsequently lipids were subjected to alkaline hydrolysis. They were dissolved in a metha$\mathrm{nol} / \mathrm{H}_{2} \mathrm{O}(10: 1$, v/v) mixture containing $15 \%$ $\mathrm{KOH}(\mathrm{w} / \mathrm{v})$ and hydrolyzed at $95^{\circ} \mathrm{C}$ for $2 \mathrm{~h}$. Lipophylic products were extracted with diethyl ether and evaporated to dryness, dis- 
solved in hexane and applied on a silica gel column equilibrated with hexane. The column was washed with $6 \%$ diethyl ether in hexane. Subsequently the polyisoprenoid fraction was eluted with $20 \%$ diethyl ether in hexane and subjected to HPLC analysis.

Chromatography. Thin-layer chromatography was performed on silica gel plates in toluene/ethyl acetate $(95: 5, \mathrm{v} / \mathrm{v})$ or on HPTLC RP-18 coated plates with a concentrating zone (Merck, Germany) in acetone with $50 \mathrm{mM}$ $\mathrm{H}_{3} \mathrm{PO}_{4}$.

Quantification of dolichol was accomplished by HPLC equipped with a $4.6 \times 60 \mathrm{~mm}$ ODS-Hypersil ( $3 \mathrm{~mm}$ ) reversed-phase column (Knauer, Germany) using a Waters dualpump apparatus, a Waters gradient programmer, and a UV detector set at $210 \mathrm{~nm}$; flow rate $1.5 \mathrm{ml} / \mathrm{min}$ in gradient A: methanol/
(Palamarczyk et al., 1980). Synthesis of DolPGlc was measured according to (Palamarczyk et al., 1990). Oligosaccharyl transferase (OT) activity was determined in the presence of DolPP $\left[{ }^{14} \mathrm{C}\right] \mathrm{GlcNAc}_{2}$ as glycosyl donor and Tyr-Asn-Leu-Thr-Ser-Val as acceptor peptide, as described in (Sharma et al., 1981).

\section{RESULTS}

\section{Deletion of $S R T 1$ gene increases activity of RER2-encoded cis-PT-ase and dolichol con- tent}

Deletion of the $S R T 1$ gene $(\Delta s r t 1)$ resulted in a three-fold higher dolichol content (Fig. 2A). There was also an increase of the RER2 encoded cis-PT-ase activity assayed in
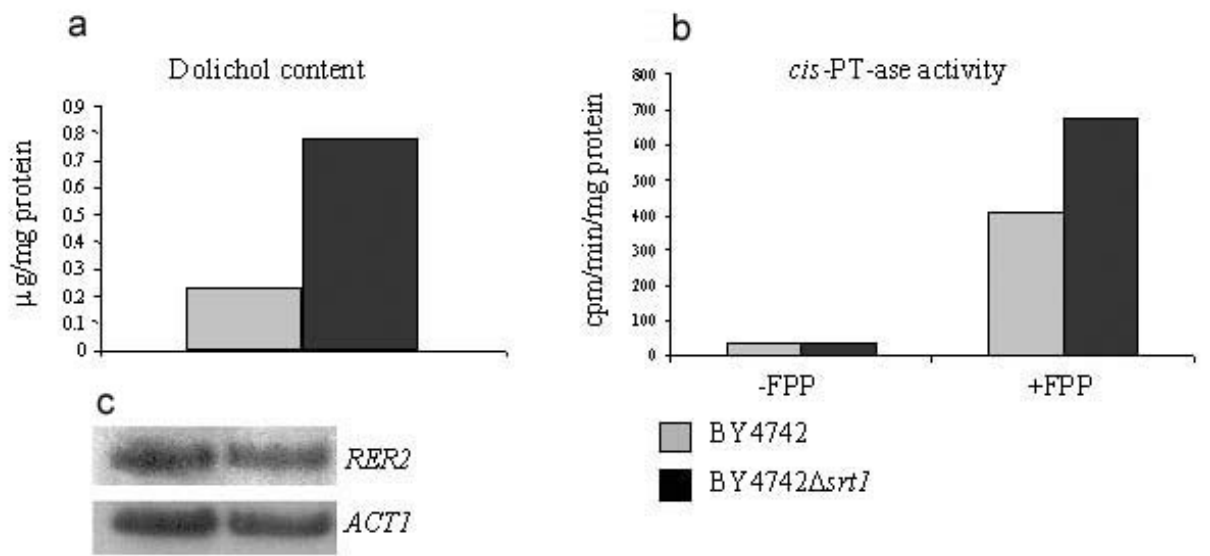

Figure 2. Deletion of the SRT1 gene increases the activity of RER2-encoded cis-PT-ase and dolichol content.

Dolichol content ( $\mu \mathrm{g} / \mathrm{mg}$ of protein) (a); cis-PT-ase activity (b); assayed without (left panel) or with (right panel) exogenous FPP. The results represent means \pm S.D. from four experiments. Northern blot analysis of RER2 mRNA (c). RNA was extracted from yeast cells in logarithmic growth phase $\left(\mathrm{A}_{600}=0.5-0.8\right)$. The same blot was probed with ${ }^{32}$ P-labelled PCR fragments representing the RER2 and, as a control, the ACT1 gene. Yeast strains: BY4742-wild type, BY4742Asrt1-strain with SRT1 gene deletion.

isopropanol/water $(12: 8: 1, \mathrm{v} / \mathrm{v})$, and solvent B: hexane/isopropanol (7:3, v/v); Dol-11 $\left(\mathrm{C}_{55}\right)$ solution was added to the samples as the internal standard.

Synthesis of glycosyl derivatives of dolichyl phosphate. Membrane fraction and the assay conditions for DolPMan and DolPPGlcNAc $_{1-2}$ synthesis were as described before vitro in the presence of exogenous FPP (Fig. 2B). The effect of the SRT1 gene deletion on dolichol content is post-transcriptional since we observe no changes in the level of RER2 mRNA in $\Delta s r t 1$ as compared to wild type cells (Fig. 2C). As expected, all dolichols, synthesized in the absence of the gene, had a chain length typical for RER2 en- 
coded cis-PT-ase products i.e., 14-17 isoprene units (Fig. 3).
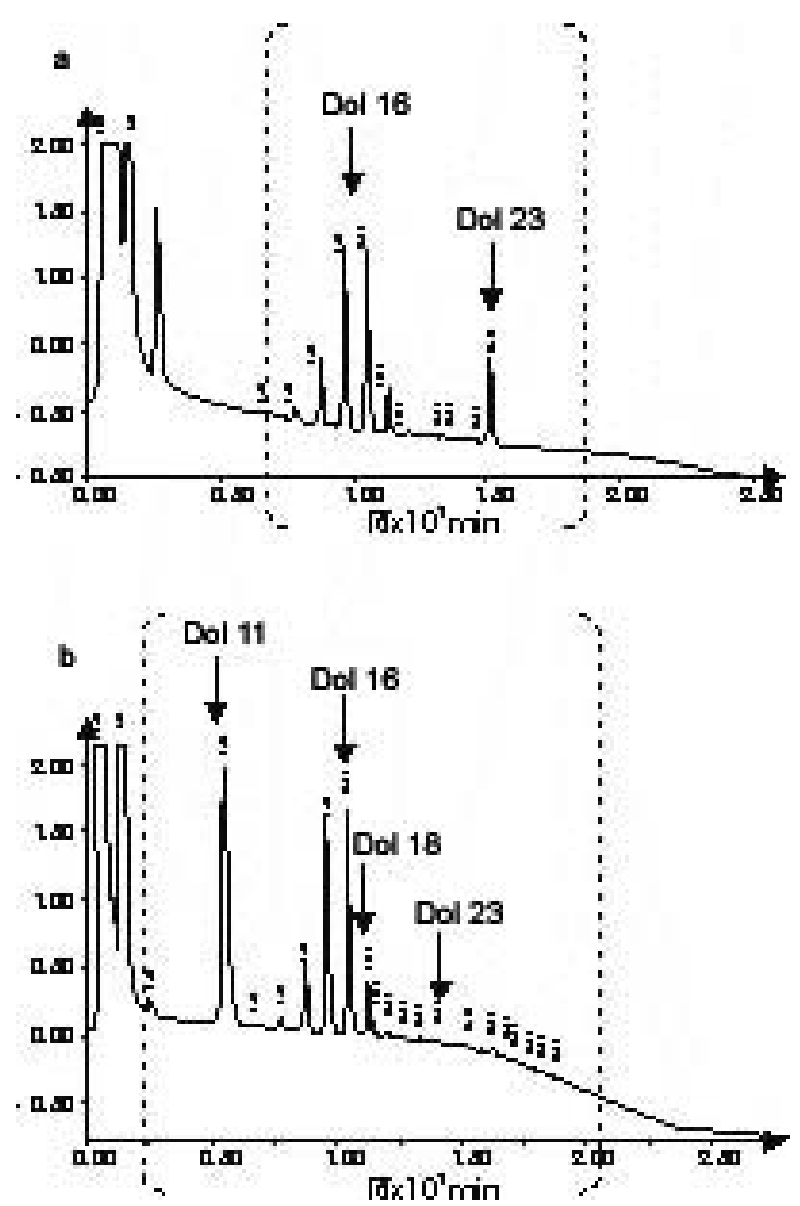

Figure 3. Inactivation of the yeast $S R T 1$ gene results in the synthesis of shorter dolichols, products of Rer2p.

(a) HPLC analyses of dolichols isolated from the BY4742 $\Delta s r t 1$ revealed presence of the molecules made up from 14-17 isoprene units. Dolichol containing 23 isoprene units (RT 15,1) was added as internal standard. (b) HPLC analyses of dolichols from wild type strain. In addition to the RER2 gene products (as in a) the molecules containing 18-23 isoprene, products of Srt1p, are visible. Dolichol containing 11 isoprene residues was added as internal standard.

\section{Overexpression of $S R T 1$ gene changes the pattern of yeast dolichols}

The SRT1 gene was overexpressed in the wild type strain from a multicopy plasmid under the PMA1 (Plasma Membrane $\mathrm{H}^{+}$ATP- ase) promoter. The dolichol pattern shifted towards longer, Srt1-synthesized species, containing 18-23 isoprene residues (Fig. 4). Moreover, quantification of the products indicated an over a three-fold increase, as compared to the wild type strain, of the total dolichol content and up to $24 \%$ reduction in

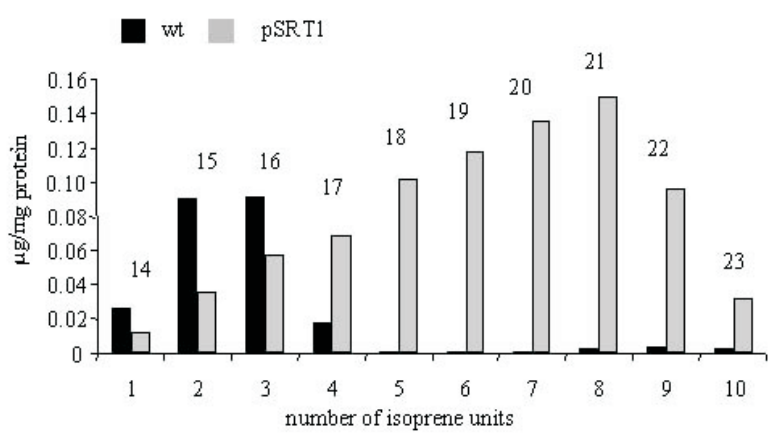

Figure 4. Overexpression of the SRT1 gene changes the yeast dolichol pattern.

The SRT1 gene, in multicopy pNEV-plasmid under PMA1 (Plasma Membrane $\mathrm{H}^{+}$ATPase) promoter, was over-expressed in the wild type BY4742 strain. Dolichols were extracted, hydrolyzed and subjected to HPLC analysis (Material and Methods). Quantities of dolichols, composed of the given number of isoprene residues, are expressed in $\mu \mathrm{g} / \mathrm{mg}$ protein in the membrane fraction. The results presented are mean values from two experiments.

the amount of dolichols synthesized by Rer2p, i.e. those containing 14-17 isoprenyl residues. Cis-prenyltransferase activity in vitro was consistenlly, although moderately increased, but only in the presence of exogenous FPP in the assay (Fig. 5A). HPTLC analysis of the products synthesized in vitro (Fig. 5B) is in agreement with the HPLC analysis of dolichols presented in Fig. 3 showing that overexpression of the $S R T 1$ gene in wild type yeast leads to the synthesis of longer dolichols containing 18-23 isoprene units. On the other hand, it has been reported (Schenk et al., 2001) that deletion of the RER2 locus is a prerequsite for SRT1 gene expression, whereas in our hands (Fig. 4) overexpression of SRT1 gene in wild type 


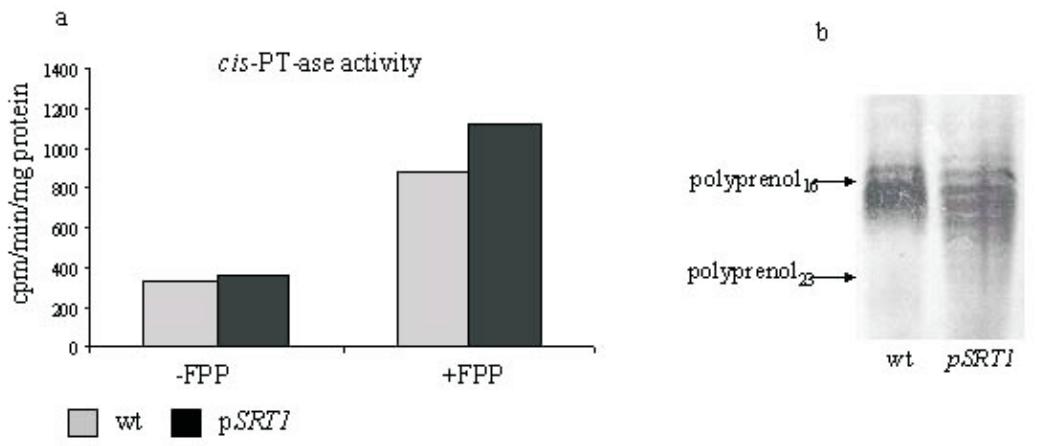

Figure 5. Overexpression of SRT1 affects cis-PT-ase activity in vitro.

cis-PT-ase activity assayed without (left) or with (right) exogenous FPP (a); the results represent means \pm S.D. from four experiments. HPTLC analysis of polyprenols synthesized in wild type cells and in cells with the SRT1 gene overexpressed (b).

yeast also leads to the synthesis of the longer polyprenol species synthesized by the $S R T 1$-encoded cis-prenyltransferase.

\section{Elevated dosage of Erg20p induces SRT1 and up-regulates RER2 and DPM1 tran- scription}

Overexpression of the ERG20 gene under the inducible GAL4/CYC1 promoter in wild type $S$. cerevisiae, concomitant with a 16 -fold increase in FPP and GPP content (Table 2),

a

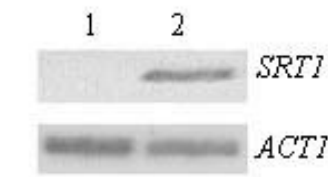

$\mathrm{C}$

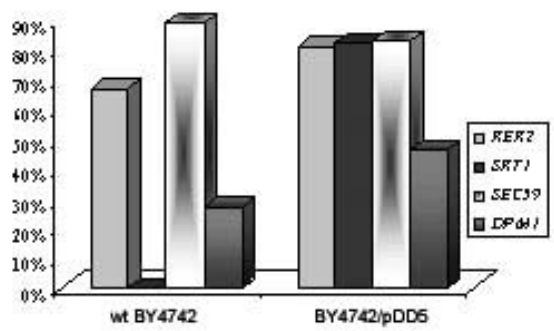

resulted in the induction of SRT1 mRNA, similar to the one observed upon inactivation of the RER2 gene (Fig. 6A). It is noteworthy that the $S R T 1$ gene induction was observed in the logarithmic phase of growth. Elevated dosage of ERG20 resulted also in an increase of RER2 and DPM1 mRNA by $20-40 \%$ and 50-80\%, respectively (Fig. 6B, C). At the same time no changes were observed in SEC59 mRNA (encoding dolichol kinase).

In the wild type strain Erg20p produces FPP and GPP in the molar ratio 3:1 (Blanchard \&

Figure 6. Overexpression of the ERG20 gene induces SRT1 and up-regulates RER2 and DPM1 transcription in wild type $S$. cerevisiae.

RNA was extracted from yeast cells in logarithmic growth phase $\left(\mathrm{A}_{600}\right.$ 0.5-0.8) cultivated on YNB medium, without nutritional markers, containing $2 \%$ galactose as a carbon source. Induction of SRT1 mRNA in $\triangle$ rer2 cells (a). RER2, SRT1, SEC59 and $D P M 1$ genes' mRNA in wild type cells and those transDPM formed with the ERG20 gene (b). The same blot was probed successively with ${ }^{32} \mathrm{P}$-labelled PCR fragments representing the RER2, SRT1, SEC59, DPM1 and, as a control, ACT1 genes. Quantification of the results from Fig. 4b, (c). Gene expression was measured using the Gene Tools v. 3.00 (Syngene) computer software and presented as the ratio of mRNA of a given gene/ACT1 mRNA level. Expression in the wild type yeast strain BY4742 was taken to be $100 \%$, with the exception of the SRT1 mRNA level, where $100 \%$ corresponds to expression in BY4242 transformed with the pDD5 (ERG20) plasmid. 
Table 2. Effect of ERG20 overexpression on FPPS activity and SRT1 mRNA level

\begin{tabular}{lllll}
\hline Yeast strain & $\begin{array}{l}\text { FPPS activity } \\
\text { (c.p.m./min per } \\
\text { mg protein) }\end{array}$ & $\begin{array}{l}\text { GPPS activity of } \\
\text { FPPS (c.p.m./min per } \\
\text { mg protein) }\end{array}$ & $\begin{array}{l}\text { FPP/GPP } \\
\text { ratio }\end{array}$ & $\begin{array}{l}\text { SRT1 mRNA } \\
\text { level }\end{array}$ \\
\hline BY4742 & $\begin{array}{l}100960 \\
( \pm 24956)\end{array}$ & 43268 & 2.3 & not detectable \\
$\begin{array}{l}\text { BY4742pDD5 } \\
(E R G 20)\end{array}$ & $\begin{array}{l}1617900 \\
( \pm 413706)\end{array}$ & 726883 & 2.2 & $100 \%$ \\
\hline
\end{tabular}

FPPS activity was measured using $\left[{ }^{14} \mathrm{C}\right] \mathrm{IPP}$ and GPP as substrates. Reaction products were extracted and analysed as described in Materials and Methods. Data represent means \pm S.D. from four experiments. The yeast cells were grown on the synthetic complete (YNB) medium containing galactose as a carbon source.

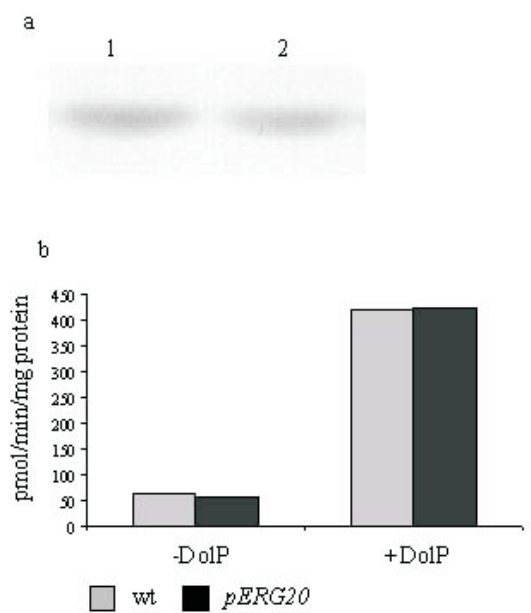

Figure 7. Increase in DPM1 mRNA does not correlate with Dpm1 protein level and its enzymatic activity.

Western blot analysis of Dpm1p expression level (a) and enzymatic activity (b) 1, wild type; 2 , transformed with the ERG20 gene under GAL4/CYC1 inducible promoter. Results of the activity assay represent means \pm S.D. from four experiments.

Karst, 1993). We assumed, however, that FPPS activities for FPP and GPP formation might change upon Erg20p over-expression. Thus, we compared the enzyme activity in a wild type strain and one with an elevated dosage of the ERG20 gene. As indicated in Table 2, the strain BY4742pDD5 (ERG20 overexpressed under the GAL4/CYC1 promoter) showed a sixteen-fold higher FPP concentration, but at the same time the ratio of FPP to
GPP remained almost identical as in the wild type control (BY4742).

We also analyzed by Western blotting the Dpm1 protein level and its enzymatic activity by incubation of the $50000 \times \boldsymbol{g}$ membrane fraction from cells overexpressing the ERG20 gene with GDP $\left[{ }^{14} \mathrm{C}\right] \mathrm{Man}$. Despite increased DPM1 mRNA, Dpm1 protein level and its enzymatic activity remained unchanged as compared to wild type cells (Fig. 7). The ability to synthesize dolichyl phosphate glucose, dolichyl diphosphate $N$-acetylglucosamine and the transfer of disaccharide from DolPPGlc$\mathrm{NAc}_{2}$ to the acceptor peptide Tyr-Asn-LeuThr-Ser-Val was also assayed. An up to $10 \%$ decrease of the activity of the glycosyl transfer catalyzed by the membranes from ERG20-transformed strain, was observed, compared to the wild type.

\section{DISCUSSION}

In the present work we provide evidence for a functional interaction between the two S. cerevisiae proteins with a cis-PT-ase activity, i.e. Rer2p and Srt1p. Deletion of the $S R T 1$ gene increases dolichol content up to three-fold. The cis-PT-ase activity measured in vitro in the presence of exogenous FPP is also increased. Since Rer2p and Srt1p are localized to different cellular compartments (Sato 
et al., 1999; 2001), Rer2p is unlikely to be regulated by a direct interaction with Srt1p. Instead, one can speculate that the enzymatic products of Srt1p, i.e. long-chain dolichols regulate the activity of Rer2p. We have suggested earlier that a specific protein complex is involved in the final step of dolichol biosynthesis (Szkopinska et al., 1997). This is in agreement with the finding (Tateyama \& Sagami, 2001) on the specific effect of biotinylated $\mathrm{C}_{80}$ polyprenal on the conversion of dehydro-dolichol to dolichol. Tateyama and Sagami's results indicate that the reduction step in the dolichol biosynthetic pathway proceeds with the recognition of the chain length of dehydro-dolichol by a $50 \mathrm{kDa}$ protein. The authors suggest that this protein interacts with the hydrophobic part of $\mathrm{C}_{80}$ dehydrodolichol, the product with maximal chain length, preventing its further elongation. Since a massive increase of long-chain polyprenol alcohols in yeast cells is concomitant with their lack of $\alpha$-saturation (Sato et al., 2001; Szkopinska et al., 1997), it might be that the interaction of Srt1p end products with Rer2p prevents further elongation of dehydro-dolichols and thus ensures saturation of their $\alpha$-residues.

Deletion of the SRT1 gene increases dolichol synthesis but does not influence the formation of glycosylated dolichyl phosphate. This result suggests that although the RER2encoded cis-PT-ase activity is up-regulated in the absence of the Srt1 protein product, the effect of SRT1 gene deletion would only be restricted to the one protein, i.e. Rer2p. Thus, we observe unchanged expression of SEC59 mRNA, encoding dolichol kinase in these cells and an almost unchanged activity of enzymes involved in the synthesis of glycosylated dolichyl phosphate. Overexpression of the SRT1 gene in wild type strain also increases dolichol formation. The over three-fold increase is due to the synthesis of the longer (18-24 isoprene units) polyprenols which are the products of SRT1-encoded cis-PT-ase. Simultaneously, an over $20 \%$ de- crease of Rer2p products (dolichols comprising 14-17 isoprene units) is observed. As mentioned in the Results section these results differ from those described by Shenk et al. (2001). Since the behaviour of RER2 depends on the genetic background (Belgareh-Touze et al., 2003) the discrepancy might be due to the different genetic background of the strains used in the experiments.

In this work we also provide evidence that the Erg20 protein not only synthesizes the substrate for the Rer2 and Srt1 proteins but also plays a regulatory role in the biosynthetic pathway of polyprenyl diphosphate which is the dolichol backbone.

Elevated dosage of the ERG20 gene, which coincides with 16-fold increase of FPP and GPP level in the cell, induces expression of SRT1, encoding an alternative cis-PT-ase, in the early logarithmic phase of growth (Table 2). Simultaneously we observe a small induction of RER2 and DPM1 expression (Fig. 5) and no effect on the SEC59 gene. On the other hand, overexpression of ERG20 has no effect on Dpm1 protein expression or DolPMan formation. This result is in agreement with our recent observation that Dpm1p expression is also regulated post-transcriptionally (Janik et al., manuscript in preparation).

Erg20p is a branch point enzyme in the biosynthetic pathway of isoprenoid lipids i.e. sterols, polyprenols, ubiquinone, heme and prenylated proteins (Song \& Poulter, 1994). FPP is also a component of the overall system of control of sterol biogenesis (Brown \& Goldstein, 1997). The most highly regulated enzyme of the isoprenoid pathway, 3-hydroxy-3-methylglutaryl-coenzyme A reductase (HMGR), has been shown to be regulated by feedback-control of its degradation (Goldstein \& Brown, 1990). In mammalian cells the signal for regulation of HMGR stability derives from FPP (Ericsson et al., 1996a; 1996b). In the yeast $S$. cerevisiae, proteasome dependent, regulated degradation of Hmg2p (one of the two proteins contributing to HMGR activ- 
ity) is also controlled by an FPP-derived signal (Hampton et al., 1996; Gardner \& Hampton, 1999). Moreover, farnesol (FOH), which may be endogenously generated within the cells by enzymatic dephosphorylation of FPP, has been shown to cause apoptotic cell death of human acute leukemia cells (Hang et al., 1994; Melnykovych et al., 1992) and growth inhibition of $S$. cerevisiae due to generation of reactive oxygen species (Machida et al., 1998). All these results confirm the complexity of the regulatory effect of FPP and its derivatives. However, nothing is known about the regulatory effect of FPP on the cis-polyprenol (dolichol) branch of the mevalonate pathway. Our results indicate that Erg20p products specifically affect the synthesis of dolichol backbone. Since wild type yeast produce FPP and GPP (Blanchard \& Karst, 1993) it is plausible that an intermediate in FPP biosynthesis, i.e. GPP or its derivatives, might also affect the expression of cis-PT-ase genes. Although no physiological role for GPP in yeast or mammalian cells has been described so far, it has been demonstrated that GPP together with FPP inhibit human mevalonate kinase activity in vitro through a competitive interaction at the ATP-binding site (Hinson et al., 1997).

In conclusion, our results suggest an indirect interaction between the yeast RER2- and $S R T 1$-encoded proteins at a post-transriptional level. Furthermore, we observe a regulatory effect of elevated dosage of the ERG20 gene on the SRT1 and RER2 gene expression, thus we postulate that the final steps of dolichol biosynthesis are controlled by the specific inter-dependence of Erg20, Rer2 and Srt1 proteins or/and their products.

We thank Dr Ludwig Lehle from the University of Regensburg for the help with oligosaccharyltransferase assay. The help of Dr. Phillip W. Robbins and Dr. Dorothy D. Pless in critical reviewing of the manuscript is gratefully acknowledged.

\section{R E F E R E N C E S}

Adair WL, Cafmeyer N. (1987) Characterization of the Saccharomyces cerevisiae cis-prenyltransferase required for dolichyl phosphate biosynthesis. Arch Biochem Biophys.; 259: 589-96.

Belgareh-Touze N, Corral-Debrinski M, Launhardt H, Galan JM, Munder T, Le Panse S, Haguenauer-Tsapis R. (2003) Yeast functional analysis: identification of two essential genes involved in ER to Golgi trafficking. Traffic.; 4: 607-17.

Blanchard L, Karst F. (1993) Characterization of a lysine-to-glutamic acid mutation in a conservative sequence of farnesyl diphosphate synthase from Saccharomyces cerevisiae. Gene.; 125: 185-89.

Brown MS, Goldstein JL. (1997) The SREBP Pathway: regulation of cholesterol metabolism by proteolysis of membrane bound transcription factor. Cell.; 89: 331-40.

Burda P, Aebi M. (1999) The dolichol pathway of N-linked glycosylation. Biochim Biophys Acta.; 1426: 239-57.

Chambon C, Ladeveze V, Oulmouden A, Servouze M, Karst F. (1990) Isolation and properties of yeast mutants affected in farnesyl diphosphate synthetase. Curr Genet.; 18: 41-6.

Cordier H, Karst F, Berges T. (1999) Heterologous expression in Saccharomyces cerevisiae of an Arabidopsis thaliana cDNA encoding mevalonate diphosphate decarboxylase. Plant Mol Biol.; 39: 953-67.

Ericsson J, Jackson SM, Edwards PA. (1996a) Synergistic binding of sterol regulatory element-binding protein and NF-Y to the farnesyl diphosphate synthase promoter is critical for sterol-regulated expression of the gene. J Biol Chem.; 271: 24359-64.

Ericsson J, Jackson SM, Lee BC, Edwards PA. (1996b) Sterol regulatory element binding protein binds to a cis element in the promoter of the farnesyl diphosphate synthase gene. Proc Natl Acad Sci USA.; 93: 945-50. 
Gardner RG, Hampton RY. (1999) A highly conserved signal controls degradation of 3-hydroxy-3-methylglutaryl-coenzyme A (HMG-CoA) reductase in eukaryotes. $J$ Biol Chem.; 274: 31671-8.

Goldstein JL, Brown MS. (1990) Regulation of mevalonate pathway. Nature.; 343: 425-30.

Grabińska K, Palamarczyk G. (2002) Dolichol biosynthesis in the yeast Saccharomyces cerevisiae: an insight into regulatory role of farnesyl diphosphate synthase. FEMS Yeast Res.; 2: 259-65.

Hampton RY, Gardner RG, Rine J. (1996) Role of $26 \mathrm{~S}$ proteasome and $H R D$ genes in the degradation of 3-hydroxy-3-methylglutaryl-CoA reductase, an integral endoplasmic reticulum membrane protein. Mol Biol Cell.; 7: 2029-44.

Hang JS, Goldner CM, Yazolvitskaya EM, Voziyan PA, Melnykovych G. (1994) Direct cell killing (apoptosis) in human lymphoblastoid cells incubated in the presence of farnesol; effect of phosphatidylcholine. Biochim Biophys Acta.; 1223: 133-40.

Hinson DD, Chambliss KL, Toth MJ, Tanaka RD, Gibson KM. (1997) Post-translational regulation of mevalonate kinase by intermediate of the cholesterol and nonsterol isoprene biosynthetic pathway. $J$ Lipid Res.; 38: $2216-23$.

Jung P, Tanner W. (1973) Identification of the lipid intermediate in yeast mannan biosynthesis. Eur J Biochem.; 37: 1-6.

Lehle L, Tanner W. (1974) Membrane bound mannosyl transferase in yeast glycoprotein biosynthesis. Biochim Biophys Acta.; 350: $225-35$.

Machida K, Tanaka T, Fujita K-I, Taniguchi M. (1998) Farnesol-induced generation of reactive oxygen species via indirect inhibition of the mitochondrial transport. $J$ Bacteriol.; 180: $4460-5$.

Melnykovych G, Haug JS, Goldner CM. (1992) Growth inhibition of leukemia cell line CEM-C1 by farnesol: effects of phosphatidylcholine and diacylglycerol.
Biochem Biophys Res Commun.; 186: 543-48,

Palamarczyk G, Lehle L, Mankowski T, Chojnacki T, Tanner W. (1980) Specificity of solubilized yeast glycosyl transferases for polyprenyl derivatives. Eur J Biochem.; 105: $517-23$.

Palamarczyk G, Drake R, Haley B, Lennarz WJ. (1990) Evidence suggesting that the synthesis of glucosyl phosphoryl dolichol in yeast microsomal membranes involves a $35 \mathrm{kDa}$ protein. Proc Natl Acad Sci USA.; 87: 2666-70.

Palmgreen MG, Sommarin M, Serrano R, Larsson C. (1991) Identification of an autoinhibitory domain in the C-terminal region of the plasma membrane $\mathrm{H}(+)$ ATPase. J Biol Chem.; 266: 20470-75.

Sagami HAY, Igarashi S, Tateyama K, Ogura K, Roos J, Lennarz WJ. (1996) Enzymatic formation of dehydrodolichal and dolichal, new products related to yeast dolichol biosynthesis. J Biol Chem.; 271: 9560-6.

Sato M, Sato K, Nishikawa Si, Hirata A, Kato Ji, Nakano A. (1999) The yeast RER2 gene identified by endoplasmic reticulum protein localization mutations encodes cis-prenyltransferase, a key enzyme in dolichol biosynthesis. Mol Cell Biol.; 19: 471-83.

Sato M, Fujisaki S, Sato K, Nishimura Y, Nakano A. (2001) Yeast Saccharomyces cerevisiae has two cis-prenyltransferases with different properties and localizations. Implications for their distinct physiological roles in dolichol synthesis. Genes Cells.; 6: 495-506.

Schenk B, Rush JS, Waechter CJ, Aebi M. (2001) An alternative cis-isoprenyltransferase activity in the yeast that produces polyprenols with chain length simmilar to mammalian dolichols. Glycobiology.; 11: 89-98.

Sharma CB, Lehle L, Tanner W. (1981) $\mathrm{N}$-glycosylation of yeast proteins; characterization of the solubilized oligosaccharyltransferase. Eur J Biochem.; 116: 101-8.

Song L, Poulter CD. (1994) Yeast farnesyl-diphosphate synthase: site directed 
mutagenesis of residues in highly conserved prenyltransferase domains I and II. Proc Natl Acad Sci USA.; 91: 3044-8.

Szkopińska A, Nowak L, Swiezewska E, Palamarczyk G. (1988) CTP-dependent lipid kinases of yeast Saccharomyces cerevisiae. Arch Biochem Biophys.; 266: 124-31.

Szkopińska A, Grabińska K, Delourme D, Karst F, Rytka J, Palamarczyk G. (1997) Polyprenol formation in the yeast Saccharomyces cerevisiae; effect of farnesyl diphosphate synthase overexpression. $J$ Lipid Res.; 38: 962-8.

Szkopińska A, Świeżewska E, Rytka J. (2002) Induction of the synthesis of an additional family of long-chain dolichols in the yeast Saccharomyces cerevisiae. Effect of starvation and aging. Acta Biochim Polon.; 49: 781-7.

Tateyama S, Sagami H. (2001) Study on the biosynthesis of dolichol in yeast: recognition of the prenyl chain length in polyprenol reduction. J Biochem.; 129: 297-302. 